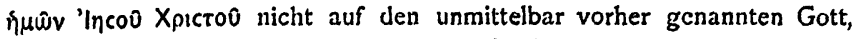
sondern auf Christus bezogen werden muß. In meinem Buche habe ich jndcssen nachzuwcisen gesucht, daß die angeführten Worte nicht Original scin können und daß die Doxologie ursprünglich Gott gegolten haben muf. Ich habe dafür verschiedene Gründe geltend gemacht, so den Zusanmmenhang mit Kap. 21, sowic dies, daß von den oiktıp auch sonst im 1 . Clemensbrief $(9,1)$ ohne den Zusatz oıd่ I. X. die Rede ist. Allein das cinfachste und wohl eindrucksvollste Argument habe ich nicht genannt. Ich möchte es darum hier nachholen. Es besteht in der Frage: wie kann man am Schluß von Kap. 20 eine Doxologie auf Christus erwarten, am Schluß eines Kapitels, das zusammen mit Kap. 19 von $\mathrm{A}-\mathrm{Z}$ der Verherrlichung Gottes, seiner Macht, Weisheit und Güte gewidmet ist? Wenn dieses Kapitel am Schlub eine Doxologie hat, so kann sie sich ursprünglich nur auf Gott bezogen haben. Es ist also offenbar der Úberarbeiter, der, um die heilsmittlerische Bedeutung Christi

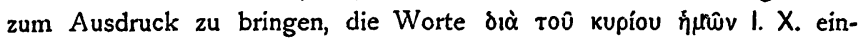
gefügt und im Zusammenhang damit die Doxologie von Gott auf Christus übertragen hat.

Sonst wüßte ich, von dieser oder jener Kleinigkeit abgesehen, meinen Ausführungen über den r. Clemensbrief kaum etwas wesentliches hinzuzufügen. Ich kann darum nur aufs neue zum Studium derselben einladen und zwar jetzt im Zusammenhang mit meiner Schrift über den I. Petrusbrief (Straßburg, Heitz, I906). Es wird sich, wie ich keinen Augenblick zweifle, bei näherer Prüfung doch noch herausstellen, daß die Geschichte des apostolischen und nachapostolischen Zeitalters eine andere Auffassung und Behandlung erheischt, als die ihr herkömmlicherweise zuteil wird.

. Amsterdam.

Daniel Völter.

\title{
Inschriftliches zur Geschichte des Gebets.
}

Das Gebiet der griechischen religiösen Texte aus der Antike hat durch die Papyruspublikationen der letzten Jahrzehnte eine überraschende Ausdehnung erfahren, sodaß die eigentlichen Inschriften dem gegenüber etwas zurückgetreten sind. Wo gibt es $z$. B. auf inschriftlichem Gebiete etwas, das A. Dieterichs Mithrasliturgie an die Seite gestellt werden könnte? Aber wenn auch nicht Schätze, so sind doch noch immer Goldkörner auf dem Acker der griechischen Epigraphik.zu finden. 
Es sei hier auf zwei größere Inschriften sakralen Charakters aus den von O. Kern edierten Inschriften der kleinasiatischen Stadt Magnesia am Mäander (Berlin, 1900) aufmerksam gemacht, die für die religiöse Terminologie der Antike im allgemeinen wie insbesondere für die Geschichte des Gebets interessant sind.

Zur Erinnerung an die Neuaufstellung des Bildes der Stadtgöttin Artemis mit dem Zunamen Leukophryene im umgebauten Tempel beschließt man eine jährlich wiederkehrende Feier mit Umzug und Festopfer, bei welcher Gelegenheit der jedesmalige iє

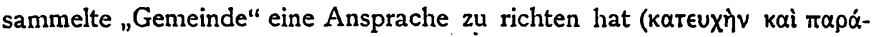

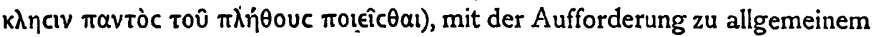
Opfer und zu Gebet an die Schutzgöttin der Stadt, das die Bitten ent-

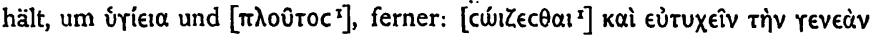

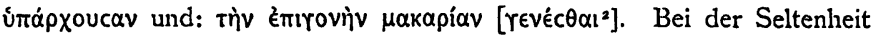
formulierter Gebetstexte aus dem Altertum ist es doppelt bedauerlich, $\mathrm{da}$ diese Inschrift des 2. Jahrhunderts v. Chr. gerade hier abbricht.

Besser steht es in dieser Beziehung mit der Vorschrift uber das Gebet am großen Zeusfeste (Magn. 98). Die Gegenstände, auf die sich das Gebet erstreckt, sind vollständig genannt $Z$. $26 \mathrm{ff}$ : : úmè

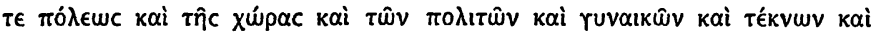

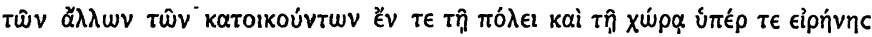

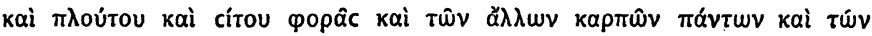

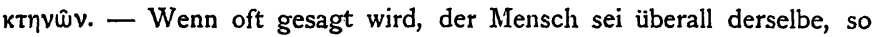
gilt das auch in religiöser Beziehung. Wer wäre bei vorliegendem Gebete nicht frappiert durch die auffallende Ähnlichkeit der Sprache mit der der alten griechischen Liturgien, wie mit unserm heutigen allgemeinen sonntäglichen Kirchengebet? Die Wohlfahrt von Stadt und Land, Friede und Gelderwerb, Getreide und andere Feldfrüchte, Viehstand - darauf richten sich die Sorgen und Bitten des Menschenherzens damals wie heute, und man könnte zumal aus ländlichen Gegenden dieses Gebet aus dem 2. Jahrhundert v. Chr. zweifellos Punkt um Punkt durch liturgische. Parallelen belegen.

Für die Gleichheit der religiösen Sprache in den verschiedenen Zeiten ist übrigens die oben zitierte Inschrift (Magn. 100 a) ein weiteres Beispiel. Von dem glücklich vollendeten Tempelbau heißt es dort, er

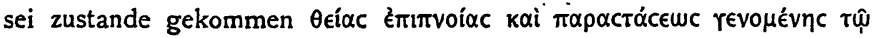

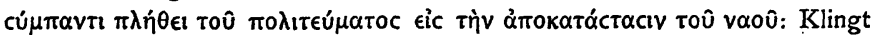

I So ergänzt Dittenberger Syllogez diese Inschrift.

2 Eigänzung von W. Dittenberger, Sylloge². 
das nicht wie aus einer Weiherede für ein christliches Gotteshaus der Gegenivart? Wenn dann allerdings einige Zeilen weiter (Magn. 100b 7. $38 \mathrm{ff}$.) dic Verheißung ăfivov Eival nötig ist, um den Hausbesitzern und biedern Werkmcistern der Stadt Magnesia cs eindringlich zu machen, der Göttin zu Ehren Altäre vor ihren Türen zu errichten und sie sauber mit Tünche zu streichen (wobei den Widerwilligen mit der Aussicht

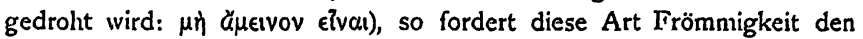
religiösen Menschen von heute notwendig zur Kritik auf. Und ebenso Magn. 98. Hier handelt es sich um die Verpflegung eines Opferstiers, der bis zum eigentlichen Festtage in freiwillige Obhut gegeben werden soll. Wer sich nun zu einer Beisteuer zu den Fütterungskosten versteht,

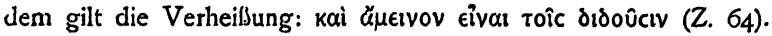

Dresden. (Lageado, Brasilien.)

G. Thieme.

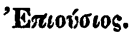

In G. Klein's gelehrter Abhandlung über die ursprüngliche Gestalt des Vaterunsers (I. Heft dieser Ztschr. 1906, S. 34ff.) ist, zumal es sich dabei um so tiefgreifende Untersuchungen wie das Verhältnis zur Johannestaufe, die Bitte um den h. Geist u. $\ddot{A}$. gehandelt, eine demgegenüber unbedeutende, überdies reichlich und überreichlich besprochene Einzelheit, nämlich die immer noch fragliche Bedeutung des Wortes $z$ tioúcıoc, unerörtert geblieben; nur indirekt konnte der Hinweis auf den Zusammenhang, in dem bei Mt die ersten drei, ja vier Bitten Erklärung und Begründung finden, wie v. 12 durch 14 . I5, so v. II durch 33.34 , dazu dienen, die ältere Erklärung (quotidianus, crastinus) $\mathrm{zu}$ beseitigen; und so ist überall dort die Bitte angeführt in der Form: "unser nötiges Brot". Näher gehen neuerdings auf diese Sache ein die Aufsätze von Lic. Dr. Gustav Hönnicke in der N. kirchl. Ztschr. v. 1906, wo S. 176 über jenes Wort so gehandelt wird, dab nach kurzer Erwähnung und Ablehnung anderer Deutungen die Erklärung Zahn's (z. d. St.) eingehende Besprechung findet. Wiedereintretend für die ältere Ableitung von $\hat{\eta}$

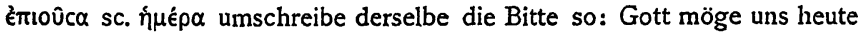
das Brot für morgen geben, eine Erklärung, die durch Berufung auf Hieronymus, der im Hebräerevangelium an dieser Stelle מָּ gefunden, ferner auf einige Übersetzungen, wie die koptische, die crastinum, und die sahidische, die venientem übersetze, begründet werde. H. gibt zu, 